\title{
ON THE INDO-EUROPEAN ABLATIVE
}

In this brief paper, it is proposed that the dental element traditionally reconstructed in the ablative singular function of Indo-European $o$-stems derives ultimately from a deictic particle in *-dh, which developed unaspirated sandhi variants that became subject to generalization in the early dialectal period. Central to this conclusion is the existence of the Greek adverbial suffix -then.

It is well known that an ablative marker in $*_{-} \bar{o} d$ is traditionally reconstructed for Indo-European, cf. Brugmann 1911: p. 165, although "ob der uridg. Ausgang ... [d or $t]$ gewesen ist, lässt sich nicht zuverlässig entscheiden, weder aus den lautgesetzlichen Verhältnissen der einzelnen Sprachen...» (Brugmann 1911: p. 164). However, in this brief paper, I wish to suggest that the original dental element found in this suffix was *-dh. My conclusion is largely based on some recent research of mine in Indo-European morphology.

In the first place, I have argued in Shields 1982a: pp. 21-84 that the inflectional system of early Indo-European was much simpler than that ascribed to the language immediately before the disintegration of the Indo-European speech community. At this early stage of development, Indo-European manifested only two gender categories (animate and inanimate), no inflectional markers for number, and only two formal casecategories (nominative and objective). Generally speaking, the marker of the nominative case was *- $\varnothing$, cf. Kuryłowicz 1964: pp. 197-1981 ${ }^{1}$, and the marker of the objective case was *-N $(m$ or $n)$. The original multi-functional role of *- $N$ is evident from the number of values it assumes in the historical dialects. For example, it is attested as a marker of the accusative

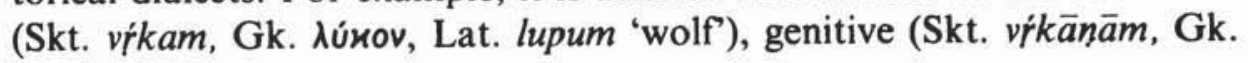

$1 *-N$ served as the exponent of the nominative in certain classes of inanimate nouns. See Shields 1982a: pp. 21-25 for details. 


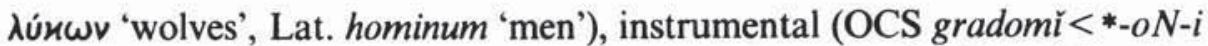
'city'), dative (Go. Pam-ma, Lith. tam-ui, OCS tom- $u$ 'that'), and locative (Skt. áśvāyām 'mare', OP schisman 'this', cf. Gray 1932: p. 192, Hitt. ketan- $i$ 'this', cf. Shields 1982a: pp. 38-40). Now Schmalstieg (1973, 1974, 1980: pp. 21-45) has proposed that within Indo-European the word-final sequence $*_{-} V N$ (short vowel plus nasal) passed to $*_{-} \bar{V}$ (long vowel) in preconsonantal sandhi position. The sandhi doublets created by this change then frequently underwent functional specialization, or one variant was generalized in the proto-language or in the dialects. For instance, "the Indo-European $1 \mathrm{st} \mathrm{sg}$. secondary ending *-om and the primary ending *-o (derived from *-om in pre-consonantal sandhi) were originally merely sandhi variants, see Szemerényi, 1970, p. 308. In general the phonologically newer form in ${ }^{*}-\bar{o}$ takes over the primary function of the present tense, whereas the older form, the ending *-om, is found in the non-present formations. Thus, ... we find the 1st sg. pres. Gk. фé $\rho \omega$, Skt. bhár-ā-mi vs. the 1st sg. imperfect Gk. है $\phi \varepsilon \rho-o v$, Skt. ábhar-am» (Schmalstieg 1974: p. 187). If one accepts this hypothesis, then it is reasonable to conclude that

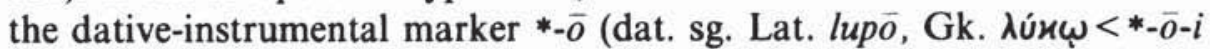
'wolf'; inst. sg. Skt. rájiña 'king', Lith. dievù $<*-\dot{u} o<*$-ó 'god') derives

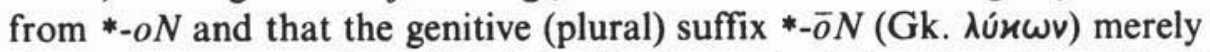
shows the passage of *-oN to ${ }^{*}-\bar{o}$ with the analogical restoration of final *- $N$, motivated by a contamination of sandhi variants, cf. Schmalstieg 1974: pp. 189-190². Most importantly, I have argued that «the traditionally reconstructed ablative suffix *-ōd (Skt. vṛ́k $\bar{a} d$, OLat. lupōd 'wolf') results from a contamination of the ending $*_{-}-\bar{o} »\left(<*_{-}-o N\right)$ with a dental marker *-T (1982a: p. 34). The fact that «the vowel was $\bar{o}$ in ordinary nominal declension alternating with $\bar{e}$ in adverbial forms (Lat. facillume $\bar{e}$ )" (Burrow 1973: p. 233) is a result of an original ablaut alternation in the stem vowel, i.e., $*_{-} o N>*_{-} \bar{o}$ and $*_{-} e N>*_{-} \bar{e}$. This alternation is, of course,

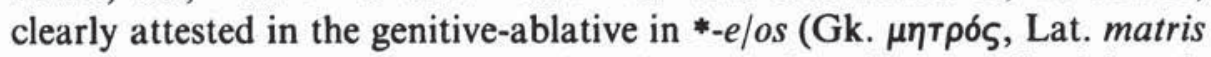
'mother'). "Apparently the $\bar{e}$-variant became largely specialized in adverbs at a later date» (Shields 1982a: p. 35). I must point out that the prevocalic variant of the old objective suffix *-oN is probably attested

\footnotetext{
2 The generalization of the suffix *-oN to other stem classes demonstrates that the stem vowel was reanalyzed as part of the desinence. "The tendency for the stem-element of the $o$-stems to be reinterpreted as a component of inflectional endings and for the resulting structures to be subsequently generalized to other nominal classes is quite common in Indo-European and the dialects" (Shields 1982b: p. 276). See Shields 1982b: pp. 275-276 for details.
} 
in ablative function in the Hittite ablative suffix - anza, «a contamination of the endings ${ }^{*}-o N$ (> Hitt. -an) and ${ }^{*}-t s$ ( $>$ Hitt. $-z=-/$ ts/)» (Shields 1982a: p. 35$)^{3}$.

«As time passed, Indo-European added to its system of declension a number of other inflectional elements - ${ }^{*}-(e / o) s,{ }^{*}-i,{ }^{*}-T, \ldots{ }^{*}-b h$ [and ${ }^{*}-e$, cf. Shields 1985] - which generally came into competition with the objective suffix $*-N$ in its oblique (non-accusative) functions. Perhaps originating as adverbial particles of some sort, cf. Markey 1979: p. 66, these new formants apparently did not completely replace the objective marker *- $N$ in the oblique functions, but rather served to increase the number of exponents a particular case function possessed. Eventually certain of these elements became the primary exponents of particular cases (and numbers); but, as has just been demonstrated, ${ }^{*}-N$ or its reflexes continued in some way or another to serve as markers of all the oblique cases into the historical dialects, although the productivity of the suffix was very limited in indicating a few of the cases. The ultimate result of all these developments was the creation of a language with a great deal of inflectional polymorphy", cf. Wandruszka 1969: pp. 218-219 (Shields 1982a: p. 40).

These new oblique markers underwent contamination not only with *- $N$ and its reflexes but also with each other. Thus, the $-z$ of the Hittite ablative suffix -(an) za represents a contamination of the oblique markers *-T and *-(e/o)s (Shields 1982a: p. 49). I believe that this Hittite nominal ending is related to the adverbial suffix *-tos with ablative force that is found in Latin, Greek, and Sanskrit (Lat. funditus 'from the bottom', Gk. Évó́ৎ 'within', Skt. mukhatás 'from the mouth'), cf. Sturtevant 1932: pp. 3-4. However, *-tos shows the $o$-grade variant of the original deictic particle ( $>$ oblique suffix) *-(e/o)s, cf. Shields 1981: pp. 270-273. The widespread utilization of such suffixes in the formation of adverbs seems to suggest their original deictic character. Moreover, the fact that some of these suffixes (or their contaminations) are limited to adverbial use in one or more dialects implies that «at a very remote stage of Indo-European, sets of deictic particles were generated which subsequently received regularized paradigmatic assignment (in the immediately pre-dialectal period). In some dialects, ... [one element] was extended at the expense of ... [another element], while in others the reverse was true» (Markey 1979: p. 65). That is, it was only after the disintegration of the Indo-European

${ }^{3}$ Since the length of the Hittite vowel here is obscure, -an-may derive from $*-\bar{o} N$, a form which shows *-oN>*-o with the analogical restoration of final *- $N$. Still, this suffix clearly attests the use of *- $N$ in ablative function. 
speech community had begun that «the formal and functional differentiation of the oblique cases" was completed (Shields 1982a: p. 96).

In Shields 1982a: p. 34, I propose that the oblique marker *- $T$, which came to be contaminated with the preconsonantal sandhi variant of *-oN to form the ablative suffix common in a variety of Indo-European dialects, probably had two phonological variants - *-/t/ and *-/d/. But now I wish to suggest that the oblique suffix *-T was originally manifested by the phoneme $* / \mathrm{dh} /$ and that the unaspirated stops traditionally associated with the ablative represent sandhi variants of *-dh which came to be specialized in this function in those dialects which preserve a dental stop in paradigmatic ablative function. Similarly, in Shields 1980, I maintain that «the dental elements which appear in the various verbal suffixes of ProtoIndo-European [i.e., ${ }^{*-t},{ }^{*}-t h,{ }^{*}-d h$ ] have a common etymological source in the earlier stages of the language. Simply, they represent specialized sandhi variants of the formant *-dh» (1980: p. 20). "It is widely held that from an early date Indo-European showed phonological alternations which were the result of external sandhi. Ward (1946: p. 102) summarizes the processes operating in the language as follows: «1. voiceless stops and spirants became voiced before voiced consonants, but it is by no means certain that they did so before vowels as well; 2 . voiced stops became voiceless before voiceless stops and spirants, and possibly in pause also; 3 . aspirates probably lost their aspiration in pause...». [I]f one assumes the original suffix to have been $*$-dh, then the other forms [i.e., *-t, *-th] can be derived from it as specialized sandhi variants" (Shields 1980: p. 24). In other words, prior to specialization, ${ }^{*}-d h$ became *-th before voiceless sounds ${ }^{4}$, and it became an unaspirated stop in pause; elsewhere it was preserved. As I demonstrate in Shields 1980: pp. 24-25, cogent arguments can be constructed for the occurrence of either *-/t/ or *-/d/as variants of *-dh in pause, although $*$-/t/ seems to be the more likely variant on the basis

\footnotetext{
4 «I wish to emphasize that my proposal does not negate the widely accepted view that voiceless aspirated stops constitute a secondary development in the history of Indo-European. Many conparativists see the derivation of */th/ "probably from IE $t+$ laryngeal' (Peeters 1971: p. 4), although 'the time of the origin of the voiceless aspirates is disputed' (Lehmann 1952; p. 81). However, Burrow (1973: p. 72) points out that despite the fact that the origin of the surd aspirates "can be attributed to a combination of IE $H$ with a preceding unaspirated surd', 'some possible cases of spontaneous aspiration in combinations with $s$ (Skt. sthag-, etc.)' must be acknowledged. Now if positing two sources for the voiceless aspirated stops is admissible, I see no problem in suggesting a third source, sandhi. In other words, all three processes would yield the new phoneme» (Shields 1980: pp. 25-26). See Shields 1980: p. 26 for further details.
} 
of natural phonological processes ${ }^{5}$. In the same way, the dental element of the ablative originally showed variants in $*_{-} / \mathrm{dh} /, *_{-} / \mathrm{th} /$, and $*_{-} / \mathrm{t} /$ (or *-/d/). The unaspirated variant was apparently subject to generalization to a large degree in the early period of dialectal development, although direct evidence for the original aspirate remains.

Interestingly enough, I believe that this evidence comes from Greek, despite the fact that a paradigmatic ablative is not found there. Of course, it is widely held that the old ablative marker of Indo-European, *- $\bar{o} T$, "survives in Greek in the Doric adverbs like ö $\pi \omega$ 'whence', Delph. Foík 'from the house'..." (Buck 1933: p. 181), but this is not the suffix which yields my conclusion ${ }^{6}$. Instead, it is the adverbial suffix $-\theta \varepsilon v$ (cf. olx $\delta \theta \varepsilon v$ 'from home', 'A $A \dot{\eta} v \eta \theta \varepsilon v$ 'from Athens', $\pi \delta \theta \varepsilon v$ 'whence?'), which «is comparable to the ablative» (Lehmann 1980: p. 149), that provides the necessary proof. In my opinion, $-\theta \varepsilon v$ constitutes a contamination of the oblique marker *-dh and the prevocalic variant of the $e$-grade of the objective suffix *-oN ${ }^{7}$. Most significantly, Greek clearly demonstrates that a marker in *-dh possessed ablative value ${ }^{8}$. Of course, in Greek this suffix -then was never regularly assigned any specialized function within nominal paradigms, but, as I pointed out earlier, such limitation of oblique suffixes to adverbial function was not uncommon in the early dialects. The situation in Greek parallels, to a large degree, the use of the oblique marker *-bh in Germanic, where «in Gothic..., -bh-forms adverbs of manner, e.g. bairhtaba, manwuba» (Markey 1979: p. 65) and remains outside nominal paradigms. Perhaps, however, the beginnings of the paradigmatic assignment of $-\theta \varepsilon v$ can be seen in the fact that uen éolien et chez Homère $-\theta \varepsilon v$ a fourni une désinence de génitif pour les pronoms personnels" (Chantrai ne 1964: p. 117). The attested function of $-\theta \varepsilon v$ in these pronouns is in keeping with the close association between genitive and ablative value, $\mathrm{cf}$. Shields 1982a: pp. 34-36.

The existence of an original deictic particle in *-dh-in Indo-European is undebatable, cf. Brugmann 1911: pp. 728-730: «Idg. dhe, dhi $[<*-d h+e, i] \ldots$

5 In Shields 1980: p. 25, I show that *-/t/ can be derived from *-/d/ as a late-emerging sandhi variant if $*-/ d /$ is assumed to be the original pausal variant. Similarly, ${ }^{*}-/ d /$ could have appeared as a variant of *-/t/. After *-/t/ had become interpreted as a morphological entity separate from *-dh, i.e., after it had become specialized.

6 These forms may actually show an original $*_{-} \bar{o},{ }^{*}-\bar{o} t,{ }^{*}-\bar{o} d$, or ${ }^{*}-\bar{o} d h$.

7 I thus reject the view of Schwyzer (1939: p. 171) and Lehmann (1980: pp. 148-149) that $-\theta \varepsilon v$ is an original postposition.

8 The $-\theta$ - of Greek $-\theta \varepsilon v$ is usually derived from *-/dh/-, cf. Brugmann 1911: p. 729, but it may actually be a reflex of either the variant *-/dh/- or the variant *-/th/-. In any event, its testimony to original aspiration is clear. 
vgl. ai. kú-ha 'wo', i-há 'hier, hierher': 1. u-bi 'wo', $i$-bi 'dort', gr. pó-thi 'wo', abg. kŭ-de 'wo', š̄-de 'hier' usw.» (Hirt 1927: p. 13). Moreover, the various sandhi forms of this element *-dh are widely attested, and its original general "oblique» function is also implied by dialectal data. For example, Greek itself shows *-/t/ in contamination with *-e in the adverbs $\pi \delta \tau \varepsilon$

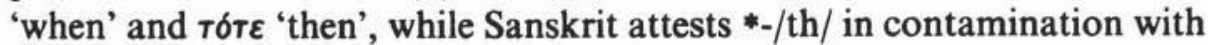
${ }^{*}-e / o N$ and ${ }^{*}-\bar{e} / \bar{o}\left(<{ }^{*} e / o N\right)$ in kathám/kathá 'how?', cf. Cohen 1984: p. $16^{9}$. The attested functional variety assumed by ${ }^{*}$-dh is especially demonstrated by the fact that it received regular nominal paradigmatic assignment in the instrumental (sg./pl.) of Hittite (-it) and in the genitive (sg.) of Tocharian (B -ntse, -mtse) (Shields 1982a: pp. 49-50). It is interesting to note that the Sanskrit adverbial suffix -tham/-tha perhaps corresponds formally to Greek -then since both appear to reflect an original IE ${ }^{*}$-dhe/oN ${ }^{10}$. The function of Sanskrit -tham/-thä, however, is best described as «instrumental». Still, when one considers that *-dh is attested as a marker of the nominal instrumental in Hittite and that $*-\bar{e} \mid \bar{o}\left(<*_{-} e / o N\right)$ is found with instrumental value in Vedic (rấjiñ 'king') and Lithuanian (dievù 'god'), it is clear that the difference in meaning is to be ascribed again to particular dialectal adaptations of oblique suffixes.

In closing, I want to point out that Cohen (1984: pp. 16-18) has recently proposed that Indo-European possessed a locative particle in *-T, «a dental stop whose exact phonetic nature $(t$ ?, $d$ ?, $d h$ ?) is unknown... This suffix then acquired several phonetic variants..." The suffix $-\theta \varepsilon v$ of Greek is, according to him, a blending of this deictic *-T and *-en; but he suggests that *en represents an occurrence of the word for 'in'. Cohen (1984: p. 19) admits that his analysis of -then is "very speculative» because of inherent semantic problems, i.e., the shift in meaning from 'in' to 'from'. Although I feel that my theory avoids such semantic problems because it is able to relate $-\theta \varepsilon v$ directly to other attested ablative suffixes and that it thereby constitutes a more general explanation of the data, Cohen's detailed arguments in support of a common etymon for all «the PIE dental stop particles» and its subsequent development of phonological variants lend support to my own hypothesis.

K. SHIELDS

9 I am actually proposing here that all the adverbial suffixes in a dental consonant, cf. Brugmann 1911: pp. 728-734, including Greek $-\theta \varepsilon,-\theta \imath,-\theta \alpha,-\theta \varepsilon v,-\delta \varepsilon,-\delta \alpha,-\delta o v$, $-\delta \eta v,-T \varepsilon$, and $-\tau \alpha$, have a common source in the deictic *-dh, cf. Cohen 1984.

10 Of course, different phonetic variants may be found in these corresponding forms, even though they are morphophonemically equivalent. 


\section{REFERENCES}

Brugmann, Karl. 1911: Grundriss der vergleichenden Grammatik der indogermanischen Sprachen. Vol. II 2. Strassburg: Trübner.

Buck, Carl. 1933: Comparative Grammar of Greek and Latin. Chicago: University of Chicago Press.

Burrow, T. 1973. The Sanskrit Language. Rev. ed. London: Faber and Faber.

Chantraine, Pierre. 1964. Morphologie historique du grec. 2nd ed. Paris: Éditions Klincksieck.

Cohen, Gerald. 1984. «Reflections on the Primitive Indo-European Locative Particles». $K Z$ 97, pp. 13-21.

Gray, Louis. 1932. «On Indo-European Noun-Declension, Especially of -o- and $-\vec{a}-$ Stems». Language 8, pp. 183-199.

Kuryłowicz, Jerzy. 1964. The Inflectional Categories of Indo-European. Heidelberg: Winter.

Lehmann, Winfred. 1952. Proto-Indo-European Phonology. Austin: University of Texas Press and Linguistic Society of America.

- 1980. «From Phonetic Facts to Syntactic Paradigms: The Noun in Early PIE». In The Indo-Europeans in the Fourth and Third Millennia: Proceedings of the Conference on Indo-European Studies. E. Polomé, ed. Ann Arbor: Karoma, pp. 140-155.

Markey, T. L. 1979. "Deixis and the $u$-Perfect». The Journal of Indo-European Studies 7, pp. 65-75.

Peeters, Christian. 1971. «A Phonemic Definition of I-E bh $d h$ gh». KZ 85, pp. 1-4.

Schmalstieg, William. 1973. «New Thoughts on Indo-European Phonology». KZ 87, pp. 99-157.

- 1974. "Some Morphological Implications of the Indo-European Passage of *-oN to *-ō». $K Z$ 88, pp. 187-198.

- 1980. Indo-European Linguistics: A New Synthesis. University Park: Penn State Press.

Schwyzer, Eduard. 1939. Griechische Grammatik. Vol. I. Munich: Beck.

Shields, Kenneth. 1980. "The Indo-European Personal Marker *-dh». Archivum Linguisticum 11, pp. 20-30.

- 1981. "On Indo-European Sigmatic Verbal Formations». In Bono Homini Donum: Essays in Historical Linguistics in Memory of J. Alexander Kerns. Y. Arbeitman and A. Bomhard, eds. Amsterdam: Benjamins, pp. 263-279.

-1982a. Indo-European Noun Inflection: A Developmental History. University Park: Penn State Press.

- 1982b. "The Indo-European Origins of the Old Hittite Directive Case». The Journal of Indo-European Studies 10, pp. 273-282.

- 1985. "Go. meina and Related Germanic Forms". Michigan Germanic Studies 11, pp. $62-70$.

Sturtevant, E. 1932. "The Ablative in Indo-European and Hittite». Language 8, pp. $1-10$.

Szemerényi, Oswald. 1970. Einführung in die vergleichende Sprachwissenschaft. Darmstadt: Wissenschaftliche Buchgesellschaft.

Wandruszka, Mario. 1969. «Polymorphie und Polysemie». In Festschrift für Hugo Moser. U. Engel, P. Grebe, and H. Rupp, eds. Düsseldorf: Pädagogischer Verlag Schwann, pp. 218-232.

Ward, Ralph. 1946. "The Loss of Final Consonants in Greek». Language 22, pp. 102-108. 